\title{
Association of Glyceraldehyde 3-Phosphate Dehydrogenase with the Membrane of the Intact Human Erythrocyte
}

\author{
Sindhchai KEOKITICHAI* and John M. WRIGGLESWORTH $\dagger$ \\ Department of Biochemistry, Chelsea College, University of London, \\ Manresa Road, London SW3 6LX, U.K.
}

(Received 30 October 1979)

1. Intact human erythrocytes were exposed to low concentrations of glutaraldehyde. After washing and subsequent lysis of the cells, glyceraldehyde 3-phosphate dehydrogenase activity is found to be associated with a membrane fraction and cannot be eluted by salt treatment. Lactate dehydrogenase activity is associated with a supernatant fraction under the same conditions. 2. Preincubation of the intact cells under conditions designed to increase internal NADH concentrations, leads to a lower membraneassociated activity of glyceraldehyde 3-phosphate dehydrogenase after lysis.

The location of 'soluble' glycolytic enzymes within the intact cell is not yet known, but it has long been suggested that glycolytic enzymes may be organized in some form of supramolecular association (Green et al., 1965; Schrier, 1967; Clarke \& Masters, 1975). Such an association must be a very loose one, since, with the possible exception of Trypanosoma brucei (Opperdoes \& Borst, 1977), no 'glycosome' has been isolated by subcellular fractionation. However, several glycolytic enzymes are found associated with particulate material after cell fragmentation under hypo-osmotic conditions. These include hexokinase (Rose \& Warms, 1967), aldolase (Strapazon \& Steck, 1977), phosphoglycerate kinase (Tillmann et al., 1975) and glyceraldehyde 3-phosphate dehydrogenase (Tanner \& Gray, 1971; Carraway \& Shin, 1972; Kant \& Steck, 1973). The latter can be found in specific association with band-III glycoprotein on the inner surface of the plasma membranes of lysed erythrocytes (Yu \& Steck, 1975). Indeed, enzyme-depleted human erythrocyte 'ghosts' have been used as specific high-affinity adsorbents for the purification of glyceraldehyde 3-phosphate dehydrogenase from various tissues (Saleemuddin \& Zimmermann, 1978).

Despite these results, studies on lysed cells remain open to criticism on the grounds of the possibility of adsorption of enzymes on to subcellular structures after lysis (Wooster \& Wrigglesworth, 1976a), and the significance of membrane association in cell

\footnotetext{
* Present address; Faculty of Pharmaceutical Sciences, Chulalongkorn University, Bangkok-5, Thailand.

$\dagger$ To whom reprint requests should be addressed.
}

lysates therefore remains a matter for conjecture. In the present paper we give evidence that glyceraldehyde 3-phosphate dehydrogenase is associated with the inner membrane surface of the human erythrocyte in the intact cell. We have used the approach of treating intact cells under mild conditions with a cross-linking reagent. The degree of association appears to be a function of cellular metabolite concentrations.

\section{Experimental}

Glyceraldehyde 3-phosphate [Sigma (London) Chemical Co., London S.W.6, U.K.] was prepared from the diethylacetal form by hydrolysis. Glutaraldehyde was obtained in aqueous $8 \%(\mathrm{v} / \mathrm{v})$ solution sealed under $\mathrm{N}_{2}$ from Polaron Equipment Ltd., Watford, Herts., U.K. All other chemicals were analytical-grade reagents of commercial origin.

For cross-linking experiments, $1 \mathrm{ml}$ of washed packed fresh erythrocytes were preincubated for $5 \mathrm{~min}$ at $4^{\circ} \mathrm{C}$ in $\mathrm{Ca}^{2+}$-free Krebs-Ringer bicarbonate buffer (Bygrave, 1966), pH 7.4, containing, where required, $0.05 \%$ glutaraldehyde. After incubation, the cells were washed twice by centrifugation and resuspension in $20 \mathrm{vol}$. of glutaraldehyde-free incubation medium. The cells were then haemolysed by suspension in $50 \mathrm{vol}$. of $5 \mathrm{~mm}$-potassium phosphate buffer, $\mathrm{pH} 8.0$, and fractions prepared as described by Dodge et al. (1963). The final suspension of 'ghosts' was in $5 \mathrm{~mm}$-phosphate buffer, pH 8.0, containing $2 \mathrm{~mm}$-mercaptoethanol.

The activity of glyceraldehyde 3-phosphate dehydrogenase was monitored at $20^{\circ} \mathrm{C}$ by following the reduction of $\mathrm{NAD}^{+}$at $340 \mathrm{~nm}$ by using a 
Perkin-Elmer SP356 dual-wavelength spectrophotometer in its dual-wavelength mode with a reference wavelength of $370 \mathrm{~nm}$. The conditions of assay were as previously described (Wrigglesworth et al., 1976). Lactate dehydrogenase was assayed as described by Gay et al. (1968).

\section{Results}

\section{Cross-linking experiments}

If fresh human erythrocytes are lysed under hypo-osmotic conditions essentially as described by Dodge et al. (1963), 73\% of the glyceraldehyde 3-phosphate dehydrogenase activity can be found associated with a membrane fraction (Table 1). As reported previously (Kant \& Steck, 1973; McDaniel et al., 1974), the enzyme can be eluted from the membranes by treatment of the fraction with $300 \mathrm{mM}-\mathrm{NaCl}$. All of the enzyme activity is then found in the soluble fraction.

Pretreatment of the erythrocytes before lysis by a brief exposure to a low concentration of glutaraldehyde results in approx. 50\% of the original total enzyme activity remaining associated with the membrane fraction after lysis. This activity cannot be removed by salt treatment (Table 1). Pretreatment of the cells with glutaraldehyde causes a loss of total enzyme activity in the lysate when compared with untreated samples. This would appear to be a direct effect of glutaraldehyde on glyceraldehyde 3-phosphate dehydrogenase, since the activity of the enzyme in free solution is inhibited by the cross-linking reagent. Association of the enzyme with the membrane slightly protects against this inhibition (Fig. 1). The biphasic nature of the inhibition curves may result from the dual action of

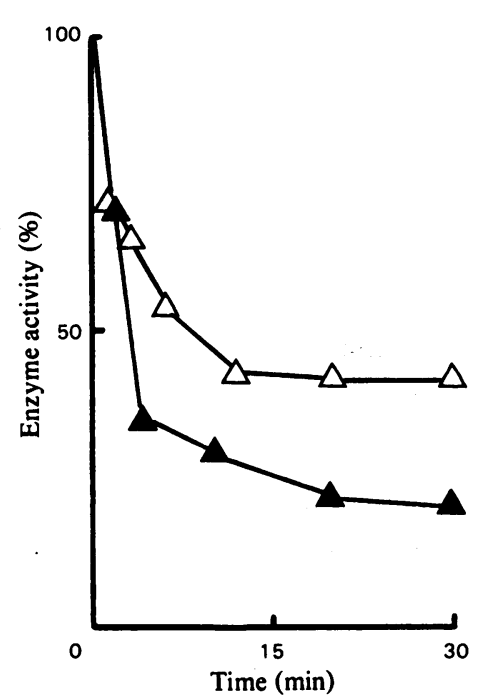

Fig. 1. Effect of glutaraldehyde on glyceraldehyde 3-phosphate dehydrogenase activity

Preparations of the enzyme were incubated at $4^{\circ} \mathrm{C}$ in $5 \mathrm{~mm}$-potassium phosphate buffer, $\mathrm{pH} 8$, containing $0.05 \%$ glutaraldehyde. At suitable intervals, samples were removed for assay. $\Delta$, Enzyme adsorbed to the membrane of lysed human erythrocytes (see Table 1 ). $\Delta$, Solubilized enzyme prepared by salt elution from the membrane preparation.

Table 1. Effect of glutaraldehyde pretreatment of intact erythrocytes on the distribution of glyceraldehyde 3-phosphate dehydrogenase and lactate dehydrogenase activity in preparations of the lysed cells

Conditions of incubation and assay were as indicated in the Experimental section. For salt elution, the membrane fraction was incubated in $300 \mathrm{~mm}-\mathrm{NaCl}$ at $0^{\circ} \mathrm{C}$ for $60 \mathrm{~min}$. The samples were then centrifuged at $20000 \mathrm{~g}$ for $20 \mathrm{~min}$ and the enzyme activity of the supernatant and pellet fractions was measured. 'Supernatant activity' is expressed as the sum of the activities of the cell-lysate and salt-elution supernatants. Numbers of experiments performed are indicated in parentheses. Abbreviation: n.d., none detectable.

\begin{tabular}{|c|c|c|}
\hline & \multicolumn{2}{|c|}{$\begin{array}{l}\text { Enzyme activity } \\
\text { (\% of total lysate } \\
\text { of untreated cells) }\end{array}$} \\
\hline & $\begin{array}{l}\text { Membrane } \\
\text { fraction }\end{array}$ & $\begin{array}{l}\text { Supernatant } \\
\text { fraction }\end{array}$ \\
\hline $\begin{array}{l}\text { Glyceraldehyde 3-phosphate dehydrogenas } \\
\text { Untreated cells }\end{array}$ & & \\
\hline $\begin{array}{l}\text { Control (7) } \\
\text { Post-lysis incubation of membrane } \\
\quad \text { fraction in } 300 \mathrm{~mm}-\mathrm{NaCl}(3)\end{array}$ & $\begin{array}{l}73 \pm 9 \\
\text { n.d. }\end{array}$ & $\begin{array}{r}26 \pm 7 \\
100 \pm 5\end{array}$ \\
\hline $\begin{array}{l}\text { Cells preincubated in glutaraldehyde } \\
\text { Control (6) } \\
\text { Post-lysis incubation of membrane } \\
\text { fraction in } 300 \mathrm{~mm}-\mathrm{NaCl}(6)\end{array}$ & $\begin{array}{l}49 \pm 14 \\
50 \pm 5\end{array}$ & $\begin{array}{l}16 \pm 20 \\
24 \pm 4\end{array}$ \\
\hline $\begin{array}{l}\text { Lactate dehydrogenase } \\
\text { Untreated cells (5) } \\
\text { Cells preincubated in glutaraldehyde (4) }\end{array}$ & $\begin{array}{l}\text { n.d. } \\
\text { n.d. }\end{array}$ & $\begin{array}{l}95 \pm 8 \\
84 \pm 14\end{array}$ \\
\hline
\end{tabular}


glutaraldehyde in reacting with the thiol group of cysteine-149 at the catalytic site as well as inhibiting changes in tertiary and quaternary protein structure by cross-linking. Loss of enzyme activity in the lysed erythrocytes could be decreased by using lower concentrations of glutaraldehyde for pretreatment, but under these conditions we have found that the membrane-associated enzyme becomes susceptible to salt elution after lysis. With higher glutaraldehyde concentrations, the cells do not lyse under the hypo-osmotic conditions used.

In contrast with glyceraldehyde 3-phosphate dehydrogenase, the distribution of lactate dehydrogenase in fractionated lysate is not significantly affected by pretreatment with glutaraldehyde under the same conditions (Table 1). Little activity is associated with the erythrocyte membranes. Most of the activity is found in the supernatant fraction after lysis.

\section{Effect of metabolites on enzyme localization}

Various metabolites have been shown to release membrane-associated glyceraldehyde 3-phosphate dehydrogenase from the membrane fraction of erythrocyte lysates (Kant \& Steck, 1973; McDaniel et al., 1974). NADH causes elution of the enzyme at concentrations in the $\mu_{\mathrm{M}}$ range (Fig. 2). Partial elution of the enzyme by $\mathrm{NAD}^{+}$, shown in Fig. 2 and also reported by Kant \& Steck (1973), is presumably due to formation of NADH by endogenous substrates, since it can be prevented by the

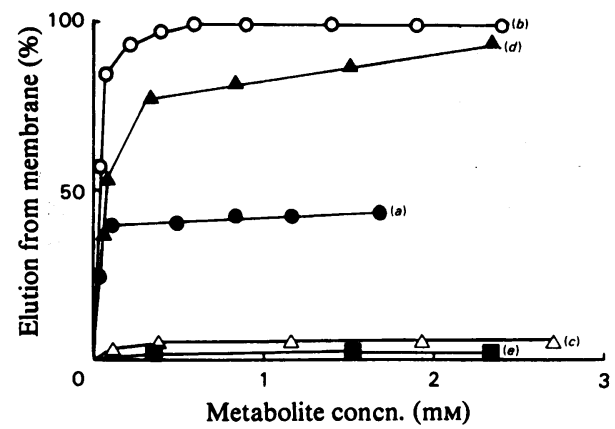

Fig. 2. Effect of various metabolites on the association of glyceraldehyde 3-phosphate dehydrogenase with preparations of erythrocyte membranes

Preparations of purified erythrocyte membranes were incubated in $5 \mathrm{mM}$-potassium phosphate buffer,

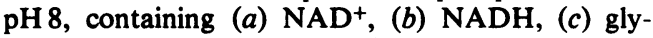
ceraldehyde 3-phosphate or (d) $\mathrm{NAD}^{+}$plus $40 \mu \mathrm{M}$ glyceraldehyde 3 -phosphate. Trace (e) shows the results of incubating the membranes in the mixture for trace $(d)$ together with $10 \mathrm{~mm}$-sodium pyruvate plus 80 units of lactate dehydrogenase (rabbit muscle type II, Sigma). presence of lactate dehydrogenase plus pyruvate in the incubation medium (Fig. 2).

Fig. 3 shows the effect of variation of the $\left[\mathrm{NAD}^{+}\right] /[\mathrm{NADH}]$ ratio on the distribution of glyceraldehyde 3-phosphate dehydrogenase between the membrane and supernatant fractions of erythrocyte lysates. From these results it can be concluded that $\mathrm{NAD}^{+}$protects against elution, and only when the ratio is $\mathbf{0 . 2}$ or lower does significant elution occur from the purified membranes.

Preincubation of the intact erythrocytes in NADH before lysis results in an increased enzyme activity in the supernatant fraction after lysis (Table 2). Millimolar concentrations were found to be necessary for this effect, presumably reflecting the relative impermeability of the erythrocyte membrane to NADH. The results shown in Table 2 suggest that the effect of NADH is on enzyme localization in the intact cell. Glutaraldehyde treatment before incubation of the intact cells with NADH prevents NADH-mediated loss of enzyme from the membrane, whereas glutaraldehyde treatment after incubation with NADH, but before lysis, does not. The membrane-associated activity of glyceraldehyde 3-phosphate dehydrogenase is also decreased when the intact erythrocytes are incubated with glucose plus lactate or lactate alone

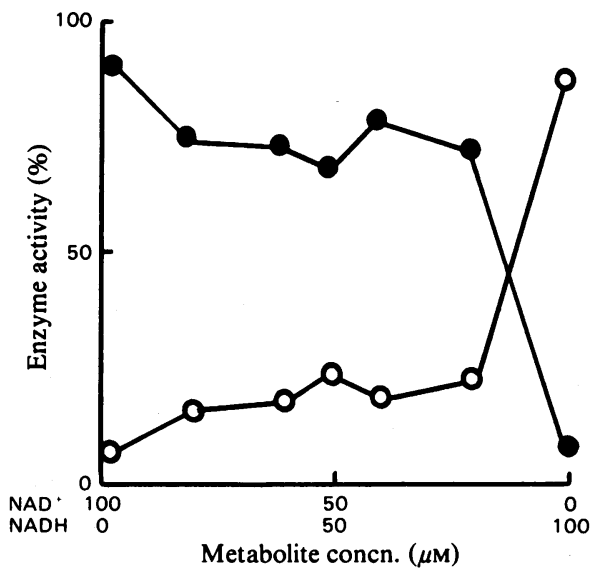

Fig. 3. Effect of the $\left[N A D^{+}\right\rfloor /\lfloor N A D H\rfloor$ ratio on the association of glyceraldehyde 3-phosphate dehydrogenase with preparations of erythrocyte membranes

Preparations of purified erythrocyte membranes were suspended in $5 \mathrm{mM}$-potassium phosphate, $\mathrm{pH} 8$, which contained $\mathrm{NAD}^{+}$and $\mathrm{NADH}$ at the indicated concentrations. After $70 \mathrm{~min}$ at $0^{\circ} \mathrm{C}$, the samples were centrifuged at $22000 \mathrm{~g}$ for $20 \mathrm{~min}$. The pellet was washed twice by resuspension and re-centrifugation in nucleotide-free phosphate buffer, and glyceraldehyde 3-phosphate dehydrogenase activity was determined in the final pellet (O) and combined supernatants (O). 
Table 2. Effect of preincubation of intact erythrocytes under various conditions on the distribution of glyceraldehyde 3-phosphate dehydrogenase activity in preparations of the lysed cells

Cells were preincubated for $30 \mathrm{~min}$ at $30^{\circ} \mathrm{C}$ in $\mathrm{Ca}^{2+}$-free $\mathrm{Krebs}-\mathrm{Ringer}$ bicarbonate buffer containing, where indicated, NADH $(1 \mathrm{mM})$, lactate $(5 \mathrm{mM})$ or glucose $(5 \mathrm{mM})$ plus lactate $(5 \mathrm{mM})$. Glutaraldehyde treatment and other conditions were as indicated in Table 1.

Conditions
Untreated cells
Cells preincubated in NADH
Cells preincubated in NADH plus $20 \mathrm{mM}^{-N A D^{+}}$
Cells preincubated in glutaraldehyde
Cells first treated with glutaraldehyde and then
with NADH
Cells first treated with NADH and then
with glutaraldehyde
Cells preincubated in $5 \mathrm{~mm}$-glucose plus
$5 \mathrm{~mm}$-lactate
Cells preincubated in $5 \mathrm{~mm}$-lactate

\begin{tabular}{|c|c|}
\hline \multicolumn{2}{|c|}{$\begin{array}{l}\text { Enzyme activity (\% of total } \\
\text { lysate of untreated cells) }\end{array}$} \\
\hline $\begin{array}{l}\text { Membrane } \\
\text { fraction }\end{array}$ & $\begin{array}{l}\text { Supernatant } \\
\text { fraction }\end{array}$ \\
\hline $\begin{array}{l}73 \pm 9 \\
10 \pm 2 \\
29 \pm 4 \\
49 \pm 14 \\
41 \pm 4\end{array}$ & $\begin{array}{l}26 \pm 7 \\
88 \pm 7 \\
59 \pm 12 \\
16 \pm 20 \\
32 \pm 8\end{array}$ \\
\hline $10 \pm 2$ & $41 \pm 6$ \\
\hline $59 \pm 5$ & $35 \pm 2$ \\
\hline $57 \pm 6$ & $39 \pm 5$ \\
\hline
\end{tabular}

(Table 2), conditions that would be expected to increase the internal NADH concentration. In contrast with the results with the purified membranes, incubation of the intact cells in solutions with an $\left[\mathrm{NAD}^{+}\right] /[\mathrm{NADH}]$ ratio of 20 did cause significant elution of the enzyme from the membrane as assessed by the activity of the enzyme in the fractions after lysis. In this case, however, the different permeabilities of the plasma membrane for the two nucleotides would be expected to exert an effect.

\section{Discussion}

On the basis of observations made on cell lysates, several investigators have suggested that there may be some form of multienzyme organization of glycolytic enzymes in the intact cell (Green et al., 1965; Schrier, 1967; Clarke \& Masters, 1975; Friedrich et al., 1977). There is evidence, again from work with cell lysates, that both glyceraldehyde 3-phosphate dehydrogenase and aldolase bind to band-III glycoprotein of the human erythrocyte membrane (Strapazon \& Steck, 1977). The present results suggest that this association may also occur in vivo. There appears to be a high degree of association of glyceraldehyde 3-phosphate dehydrogenase with the human erythrocyte membrane in the intact cell. The extent of this association can be modified by treatments which alter the intracellular concentration of NADH, analogous to the effects of $\mathrm{NADH}$ on the adsorption characteristics of the enzyme in cell lysates.

The results of treatment of erythrocytes with low concentrations of glutaraldehyde before lysis are consistent with a cross-linking of the enzyme to the membrane of the intact cell. A significant interaction of glutaraldehyde with the enzyme after lysis of the cells is unlikely. Low concentrations $(0.05 \%)$ of glutaraldehyde are used for pretreatment, and the intact cells are washed twice in iso-osmotic buffer solution after pre-treatment but before lysis. Dilution during hypo-osmotic lysis would lower the concentration of any remaining glutaraldehyde to less than $0.001 \%$, a concentration that we have found to be too low for any significant cross-linking to take place. In addition, the cross-linking experiments in the presence of NADH before and after glutaraldehyde treatment clearly indicate glutaraldehyde fixation of the enzyme to the membrane before lysis occurs. Specificity in enzyme localization by the cross-linking technique is shown by the fact that lactate dehydrogenase activity is always associated with the supernatant fraction under the same conditions.

What could be the physiological significance of the membrane association of glyceraldehyde 3phosphate dehydrogenase? Some form of metabolite compartmentation in erythrocyte glycolysis has been suggested by Niehaus \& Hammerstedt (1976), on the basis of the kinetics of incorporation of extracellular $\mathrm{P}_{1}$ into ATP in the intact cell, as well as by Friedrich et al. (1977), who have used $\alpha$ glycerophosphate dehydrogenase as an 'enzyme probe' to test whether certain metabolites are accessible to the bulk medium in concentrated preparations of sonicated erythrocytes. Some degree of channelling of glycolytic intermediates is suggested by these and the present experiments, and this may be expected to have a profound effect on the 
flux characteristics of glycolysis in the intact cell (Katchalski et al., 1971; Mosbach, 1976; Wooster \& Wrigglesworth, 1976b). The close association of glyceraldehyde 3-phosphate dehydrogenase with phosphoglycerate kinase, another enzyme found to be associated with the membrane fraction after erythrocyte lysis (Tillmann et al., 1975), may also help to control the intracellular concentrations of 2,3-bisphosphoglycerate, a physiological regulator of haemoglobin oxygen affinity (Benesch et al., 1971; Brewer \& Eaton, 1971).

We thank Professor Harold Baum and Dr. Peter Quinn for discussions. S. K. acknowledges support from Faculty of Pharmaceutical Sciences, Chulalongkorn University, Thailand.

\section{References}

Benesch, R. E., Benesch, R., Renthal, R. \& Gratzer, W. B. (1971) Nature (London) 234, 174-176

Brewer, G. J. \& Eaton, J. W. (1971) Science 171, 1205-1211

Bygrave, F. L. (1966) Biochem. J. 101, 480-487

Carraway, K. L. \& Shin, B. C. (1972) J. Biol. Chem. 247, 2102-2108

Clarke, F. M. \& Masters, C. J. (1975) Biochim. Biophys. Acta 381, 37-46

Dodge, J., Mitchell, C. \& Hanahan, D. (1963) Arch. Biochem. Biophys. 100, 119-130

Friedrich, P., Apro-Kovacs, V. A. \& Solti, M. (1977) FEBS Lett. 84, 183-186
Gay, R. J., McComb, R. B. \& Bowers, G. N. (1968) Clin. Chem. 14, 740-753

Green, D. E., Murer, E., Hultin, H. O., Richardson, S. N., Salmon, B., Brierley, G. P. \& Baum, H. (1965) Arch. Biochem. Biophys. 112, 635-647

Kant, J. A. \& Steck, T. L. (1973) J. Biol. Chem. 248, 8457-8464

Katchalski, E., Silman, I. \& Goldman, R. (1971) $A d v$. Enzymol. 34, 445-536

McDaniel, C. F., Kirtley, M. E. \& Tanner, M. J. A. (1974) J. Biol. Chem. 249, 6478-6485

Mosbach, K. (1976) FEBS Lett. 62, E80-E95

Niehaus, W. G. \& Hammerstedt, R. H. (1976) Biochim. Biophys. Acta 443, 515-524

Opperdoes, F. R. \& Borst, P. (1977) FEBS Lett. 80, 360-364

Rose, I. A. \& Warms, J. V. B. (1967) J. Biol. Chem. 242 , $1635-1645$

Saleemuddin, M. \& Zimmermann, U. (1978) Biochim. Biophys. Acta 527, 182-192

Schrier, S. L. (1967) Biochim. Biophys. Acta 135, 591-598

Strapazon, E. \& Steck, T. L. (1977) Biochemistry 16, 2966-2970

Tanner, M. J. A. \& Gray, S. R. (1971) Biochem. J. 125, 1109-1117

Tillmann, W., Cordua, A. \& Schröter, W. (1975) Biochim. Biophys. Acta 382, 157-171

Wooster, M. S. \& Wrigglesworth, J. M. (1976a) Biochem. J. 153, 93-100

Wooster, M. S. \& Wrigglesworth, J. M. (1976b) Biochem. J. 159, 627-631

Wrigglesworth, J. M., Keokitichai, S., Wooster, M. S. \& Millar, F. A. (1976) Biochem. Soc. Trans. 4, 637-640

Yu, J. \& Steck, T. L. (1975) J. Biol. Chem. 250, 9176-9184 